\title{
MILITARY MUSIC IN SOUTH-AFRICA: A CRITICAL STUDY OF ITS USE IN TIME OF PEACE AND ITS POTENTIAL IN TIME OF WAR, TOGETHER WITH CONSTRUCTIVE IDEAS FOR INCREASING EFFICIENCY. SGT F.A.M. COUSINS*
}

Congreve assures us -

'Music hath charms to soothe a savage breast To soften rocks, or bend a knotted oak.'

A sentiment echoed softly by Cowper: 'With melting airs, or martial, brink, or grave, Some chord in unison with what we hear Is touched within us, and the heart replies.'

Longfellow's cry is more prosaic:

'Music is the universal language of mankind.'

And no doubt he would have nodded wisely at Kamahal's way of putting it . . .

'Music has a fantastic way of getting a meaning across.'

Certainly the power of music in all fields, and not least the military field, has proved itself throughout the ages. From Purcell to 'Pop'. From Beethoven to Burlesque. From the hymn Rock of Ages to the 'Rock' of hysterical teenagers. We may have marvellous music, intriguing music, deplorable music, but none dare deny its power to influence the mind and spirit of man - in peace and in war.

War, it would seem, spawns its special genus of musical influence spurring on men to deeds of valour and its peoples to endure. Instances are legion. From the American Civil War we gained such endearing songs as Marching Through Georgia; John Brown's Body; and When Johnny Comes Marching Home. Out of the Boer War came Goodbye Dolly Gray, and Marching to Pretoria. The 1914-18 holocaust gave us Tipperary; Keep the Home-fires Burning, and Pack Up Your Troubles - to name but a few. The years 1939-45 produced a less nostalgic and more boisterous crop: Lili Marlene; Roll Out The Barrel; Beer Beer Glorious Beer; We'll Hang Out The Washing On The Siegfried Line, and others equally carefree .... and sometimes unprintable!

Future conventional wars will no doubt give birth to more such enduring melody. History is rich in instance of singing soldiers, military bands, and bagpipes colouring the morale of troops and implanting dismay in their enemy. Philip Howard, in his history of The Black Watch regiment, vividly describes the airborne invasion of Crete in $1942 .^{2}$ How the Highlanders had to go in with bayonets . . .
The pipers played the Battalion in with 'Highland Laddie' the Regimental march, and 'The Black Bear'. This last tune has a pause for a yell at intervals, and is traditionally played when a final effort is needed from tired men.

Again, of the same regiment we read (in the attack on Kumasi, 1874)

and the Companies wheeled off into the bush. 'The skirl of the pipes roused the Scotsmen to a fury, and, like a disciplined avalanche, they rushed forward.

And was it not Piper George Clark at Vimiera (1808) badly wounded in the groin while playing his company forward, but remarking 'Deil ha' my saul, if ye shall want music'; continued his tune while stretched bleeding on the ground. ${ }^{3}$

These brief examples might suffice to remind us of the importance of music in time of war if the justifiably impatient do not cry, 'Bagpipes! — but what of Military Bands?' Perhaps, then, at the risk of a further quotation, we might look briefly at the battle of Isandhlwana of 100 years ago: ${ }^{4}$

everyone was pretty sick; the first 24th had lost their queen's colours, their band instruments and had been fearfully cut up both in officers and men. The second 24th had lost both their colours, their band, and a lot of officers and men.

In South Africa today we have a plenitude of military bands, brass bands, and cadet Bands. These latter (consisting purely of trumpets, bugles and drums) hold continuous competitions. The role of the brass band, as yet, appears to be more of a spawning ground for future brass instrumentalists than that of a serious functional unit. It functions, yes, in back-waters and by-ways, but it cannot rank with the highly sophisticated and musical brass band of the American and English cult, found also in a lesser degree in France, Germany and Italy. With leadership this will come.

The Military Band in the SADF (with its special composition of brass and woodwind) has reached 


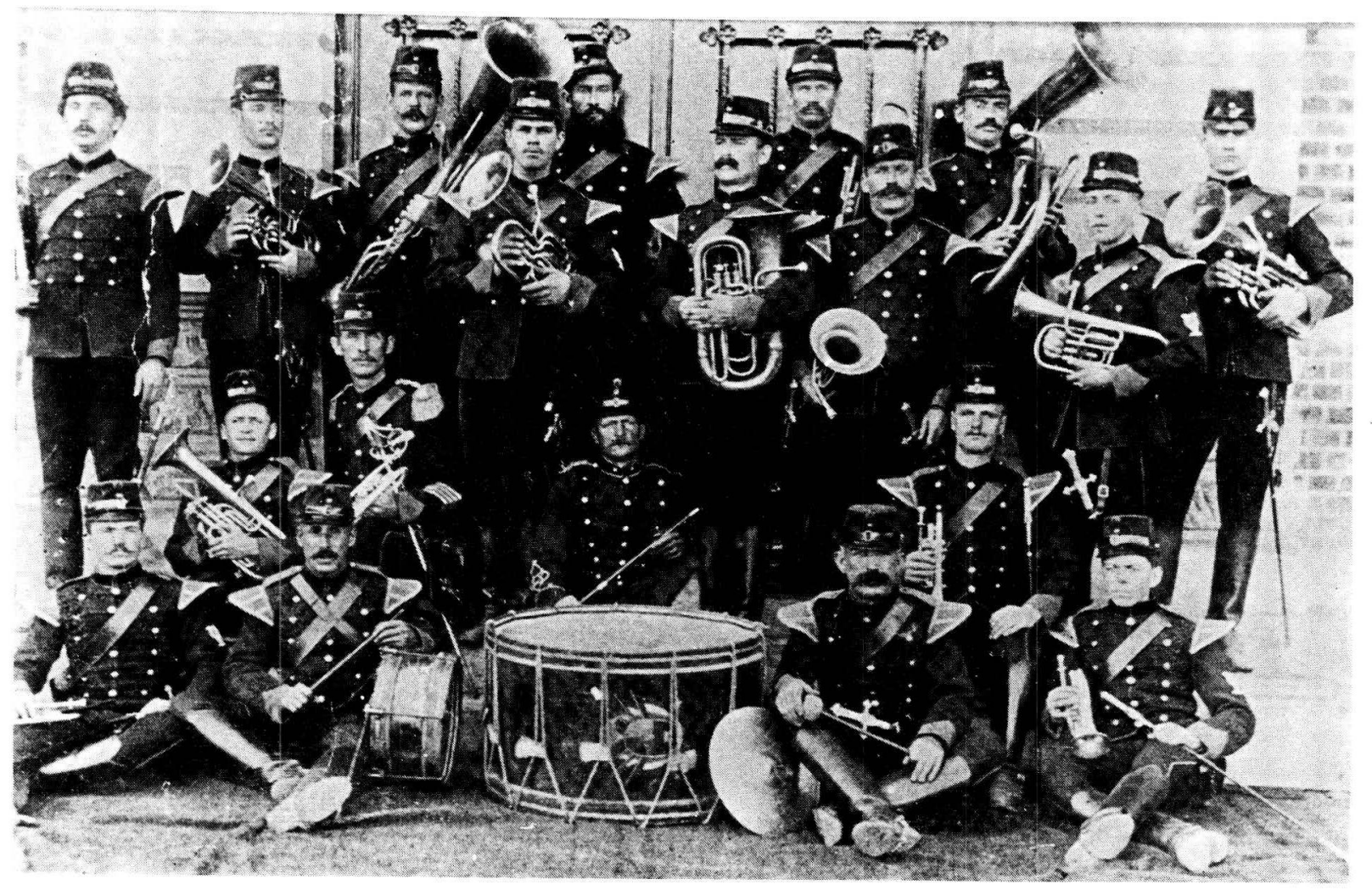

Orchestra of the ZAR State Artillery

an acceptable maturity, but, as we shall discern, within limits. Nevertheless, despite present criticism, it is not to be underestimated. From its ranks can be drawn music suitable for any occasion, whether for Ceremonial functions, Funerals, Church services, or serious music concerts. It can also provide smaller groups within the unit capable of 'Dixieland', Dance-music, or even 'Pop'. Curiously, in fact (until recently), one SADF band, using members who were double-handed, provided a string quartet which functioned admirably in the background at more than one military reception and cock-tail party. And it is not uncommon for a wind-ensemble to perform Bach, Mozart and Beethoven at similar functions.

This is the Peace-time story of the military band. It is also a part-time story. For, although fully active as regards pay and hours employed, the output is well below potential. Much time is spent in relatively aimless rehearsing. Time can certainly be better used in, say, playing to local troops at lunch hour (purely as back-ground music, of course, and therefore at a non-interfering distance). This would represent positive morale building. And then again, why should not small groups invade the various Service bars in the evenings? When this happens spontaneously, as it accasionally does, it is always without exception greatly appreciated. Morale building again. Of course, on no account must the sound-level even begin to approach that of the dreaded discoteque. This essential requirements is accomplished automatically, provided that all electronic amplifiers and equipment are totally dispensed with Discretion must be the watch-word.

The currently popular 'pop' once picturesquely described as the 'mindless three-letter-word of music' can scarcely be considered as a musical medium to be encouraged. Such musical epilepsy is surely a dangerous disease? At the other end of the spectrum, neither need we indulge in Beethoven quartets. Then, what should be encouraged? Symphonic music, even in military-band guise, is guaranteed to thin out a Service audience, and a string quartet to lower the temperature of the already empty concert hall from which the captive and desperate audience 
will have somehow escaped. Hence the field is narrowed to Musicals and Military Bands, and, since a Musical is virtually immobile and expensive to produce in terms of time and money, it will be seen that we have, through the principle of reductio ad absurdam, arrived at a Military Band in all its divergent facets. A most satisfactory conclusion to our argument as a military band is both mobile and in being - and in uniform.

Let us now analyse further the uses of a military band. As we have observed it can provide a wide spectrum of musical activity mostly acceptable to the majority of the public and therefore to the Serviceman. We may assume correctly that the obvious and most popular function of a military band is to march through the streets in its own right causing John Citizen to pause a moment and move on with spirits uplifted. A function which is rarely indulged in. Equally uplifting to the spirit is the military band performing on a park bandstand. But it seldom does today, though it used to with regularity. Even the smallest band-stand, such as is to be found in the De Waal Park, Capetown, can accommodate 19 players, a sufficient combination on a Sunday afternoon but, the band-stand remains empty. There are City Squares, Zoos, and grass-corners in plenty - all silent and unused. And where are the military musicians? In their bandrooms endlessly rehearsing to little benefit.

But does all this matter? Is improvement necessary? Is it not sufficient to have a band available for Ceremonial parades, Funerals, Church Services, and a Dance section for social requirements? Good enough is good enough, it can be claimed. But wait! - Would not a band capable of broadcasting reach a wider public? That public from which is drawn the young men who will have to fight to maintain our Country's freedom. Only through the medium of radio and television can the image of the army, navy and airforce be widely and regularly distributed. But the S.A.B.C. will not, and rightly, broadcast music of any kind which is not up to normal professional standards. And our Service Bands have not

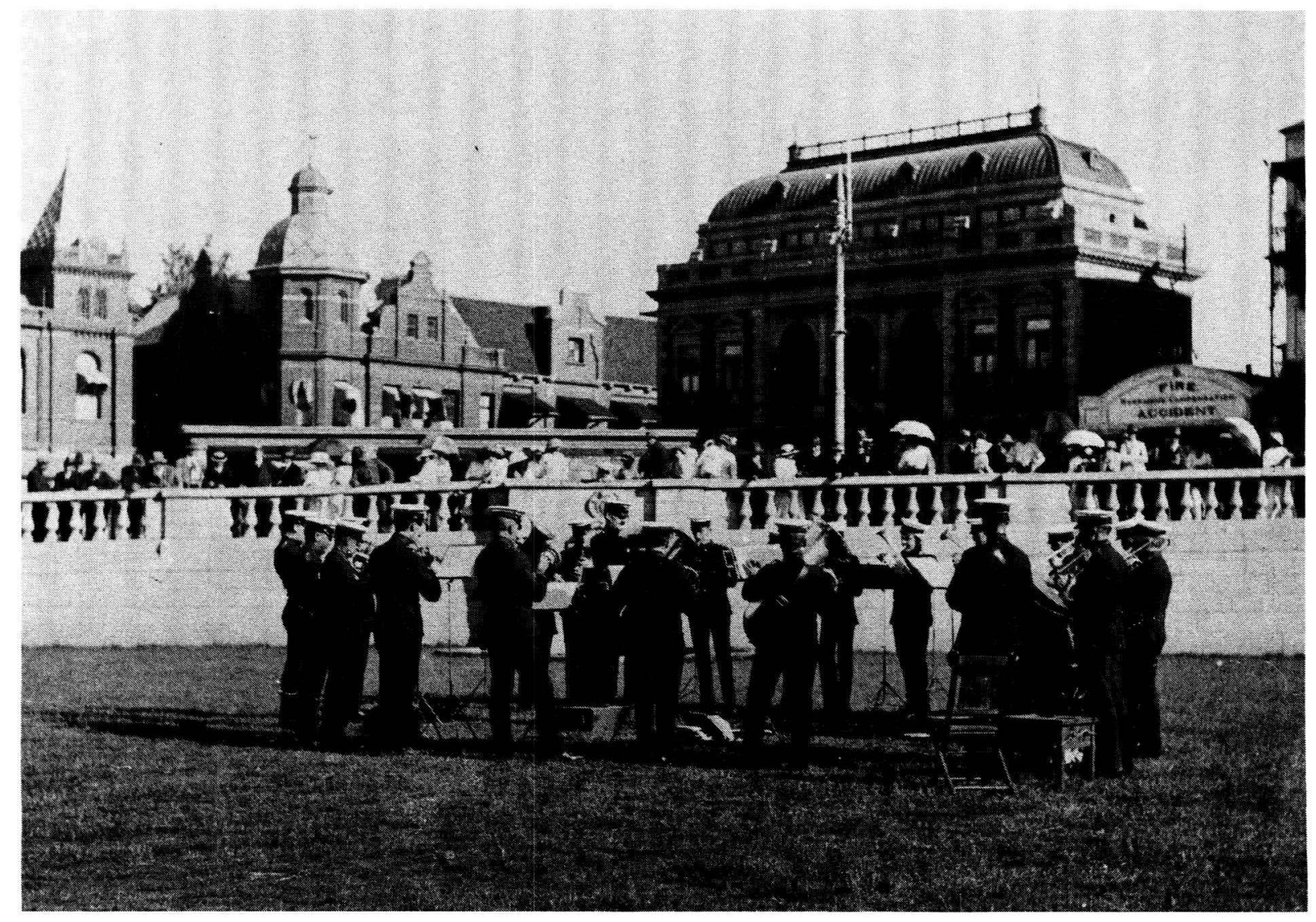

SA Army orchestra on Church Square (date unknown). 
attained - and cannot attain - that standard under existing influences. This is not in dispute. The stirring strains of a military band broadcast was recognised as an important emotional aspect of the Services in the United Kingdom during the dark days of World War 2. All the senior bands (and less senior bands) did regular Home and Overseas broadcasts, including the hour-long marathon for local factory consumption known as 'Music While You Work' programmes.

An understanding of the Military Band demands an understanding of its composition. An analysis is a sine qua non. In South Africa this analysis can only be arrived at if the military band is seen within the context of the musical world at large. Regretfully it has to be admitted that our military bands are at the bottom of the pile where 'straight' music is concerned. This will seldom be admitted, but it is manifestly the truth. The players cover a social and musical spectrum ranging from the near-illiterate to the cultivated. They fall into often overlapping categories:

(a) ex Brass band (as often as not from the Salvation Army)

(b) Wind-players who are drop-outs from the free-lance dance music world, and seek security.

(c) Wind-players who have been unable to make the grade in the symphony business.

(d) Symphony players who have had to step down due, usually, to the ageing process and subsequent loss of 'edge'.

There is a fifth category found today: a sprinkling of $C$. F. young men who play, or are attempting to play, some windinstrument. Naturally enough they opt for a band in lieu of the usual form of compulsory military service. This element (often highly intelligent, musical and useful) we have to discount. They come. They go. They do not disrupt the picture.

Occasionally those in category (c) succeed in the course of time, and through diligent practice, in becoming sufficiently competent to get into the fringe of the symphony business. Military music cannot hold their interest.

As in most organisations the key figure is the man at the top. In our context it is the Director of Music (or Bandmaster, as some would have it). We have seen that he is expected virtually overnight to become excellent in Administration. Personnel Management, and Conducting, without, as a rule, having had even the most rudimentary instruction in any one of these most intricate activities. It is amazing that some do as well as they do, though most D. of M's are in the course of time able to cope sufficiently well with at least one of the required disciplines. 'Friends of Truth' Condorcet reminds us, 'are those who seek it, not those who boast of having found it.' ${ }^{6}$

What is the answer? Perhaps we should raise our eyes to the bands overseas. They operate in an entirely different manner, and with proven success.

The Bands of the Brigade of Guards (based in London) are an example of a system which has been arrived at through decades of trial and error. It is a system designed to attract and to hold the services of a certain type of musician. He is the free-lance musician from the theatre pit, the dance band, the symphony world and the commercial studios. He is anxious to supplement, within the security of the Service, his sometimes precarious livelihood. He is versatile and professional. Although his membership of a Service band naturally enough takes precedence over his civilian activities, he finds himself for the most part free to pursue his free-lance work. In fact, he is encouraged to do so and is often given 'Watchkeepers' leave where there is a conflict of interests!

The basic conditions offered to musicians in the Guards Bands are as follows:

(1) Uniforms worn only for engagements.

(2) Rehearsal hours as in the professional musical world (i.e., 10 a.m. - 1 p.m.)

(3) Musicians first and soldiers second, despite falling under the full umbrella of the Services.

(4) 12 year contract with option of Discharge purchase.

This system may puzzle the uninitiated and certainly the regular South African serviceman. But it must be remembered that, generally speaking, a soldier is not a musician, and a musician is not much of a soldier - unless, he abandons music and takes up soldiering full-time. It may rile South African military musicians to have mention of their overseas counterparts. But facts cannot be ignored, and history has much to teach. Is it not a challenge to discover that in 1762 the first Gunner Band was formed and established at Woolwich. 
(This 'Band of Musick' consisted of eight players in whose Articles of Agreement it was clearly stated that in addition to performing on wind instruments they 'must be capable to play upon the violincello, bass, violin and flute'. Thus was born the requirement, which still holds good today, that every Royal Artillery musician must be proficient upon both a military band and an orchestral instrument. ${ }^{\text {? }}$

These accomplishments are nurtured in the Junior Musicians Troop of the Royal Artillery at Woolwich to this day. This troop provides the majority of the musicians for the senior bands. In the main the Troop consists of school leavers who are already accomplished musicians before joining: they receive two years' musical tuition at Woolwich followed by a year of study at the Royal Military School of Music, Knel!er Hall. Altogether there are three RA bands. They travel widely, thereby upholding in their own sphere the Royal Artillery's battle honour - 'Ubique,' meaning Everywhere.
Furthermore, to the picture of the British bands (the RA, the Guards, the Household Cavalry, the Royal Marines at Portsmouth, and the Royal Airforce) must be added the fact that they make a special point of limiting, as far as is humanly possible, what is known in the South African Defence Force bands (somewhat vulgarly!) as 'The Crap'. This expression is a composite for such things as time-wasting, 'bull-dust' (lies), unnecessary roll-calls, wasteful rehearsals, and over-regimentation. Not least the deliberate denigration subtly practised by some senior ranks, which is probably no more than thinly disguised sadism. The 'Crap' accumulates in small amounts - as in lead poisoning - until the threshold of tolerance is reached. Then may come the fatal dose and the affected (or infected) party strikes camp - and yet another musician is lost to the unit. (In a psychological climate where respect for authority and self-discipline is commanded and not demanded, there is little problem.)

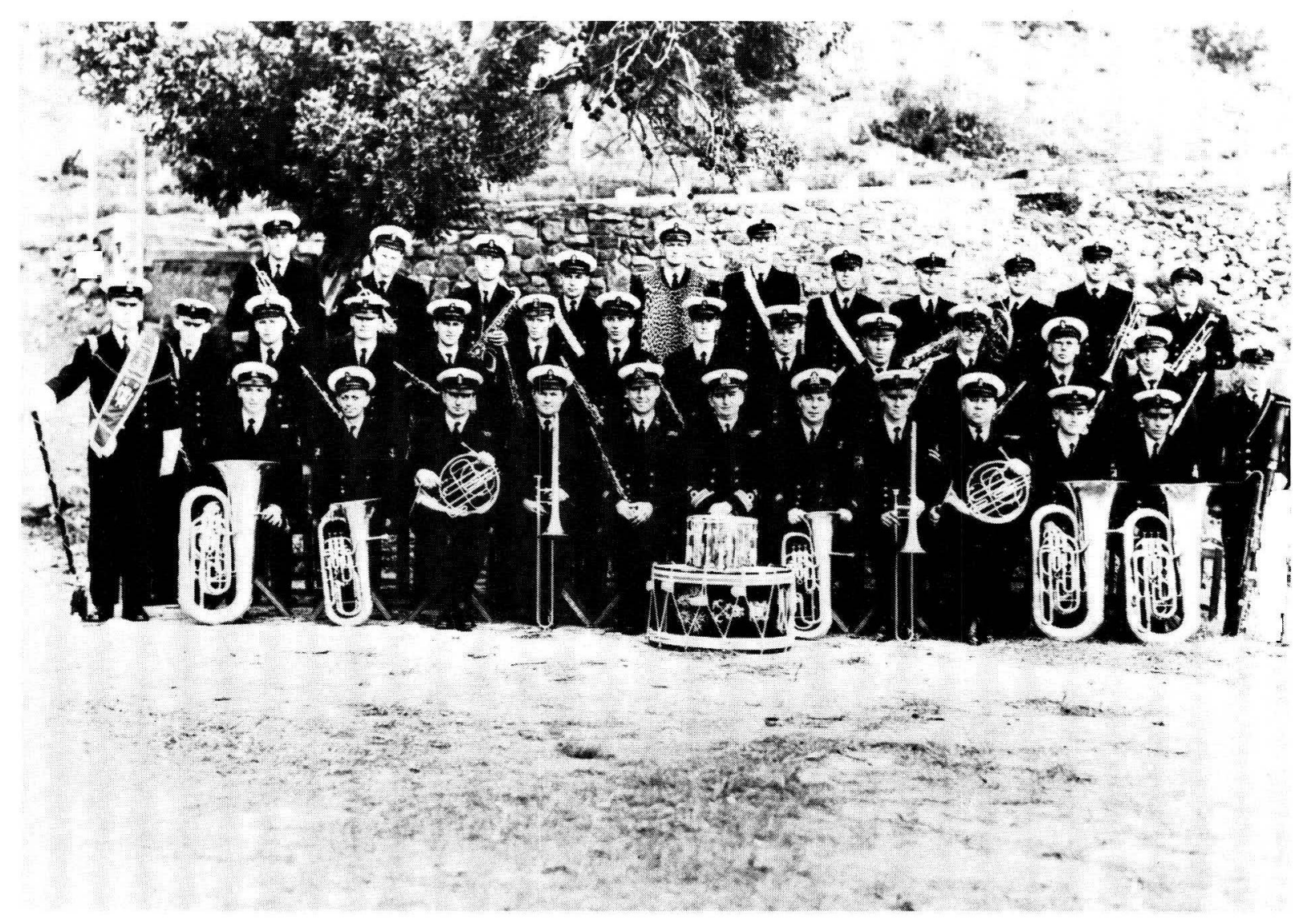

SA Navy orchestra under direction of Lt Cdr J. Imrie. 
The morning rehearsal hours commencing at 10 a.m. eliminate much time-wasting, and yet offers the invaluable opportunity of private practice (without which a musician is not worthy of the name). This is of particular value to the wood-winds (clarinets, oboes, flutes and bassoons). It can be done in their own homes at the most profitable time - the beginning of the day.

The Directors of music in the Guards Bands áre required to have attended that age-old institution, Kneller Hall, designed in part to turn out highly trained Bandmasters. For bandmastership Kneller Hall is a four-year course, and its graduates are respected throughout the world. Due to the combination of adequate Directors and improved personnel, bands of the Brigade of Guards gain regular spots in the broadcasting service.

But this is not so in South Africa. As we have observed, the standard of playing is not acceptable for broadcasting, and nothing is done about it. Small wonder that SADF bandsmen are classified as operatives and not as artisans.

It might reasonably be concluded that, until such time as South Africa can provide trained Directors of music, a solution might be to canvass Kneller Hall for future applicants. The lack of adequate bilingualism, which would be temporary, need not be a problem. There are crash-courses in Afrikaans, and in any case every band has a band sergeant-major who can iron out language difficulties. The alternative is the status quo - an unsatisfactory situation. This situation, it must be said, incorporates the reasons - nay! excuses that musicians give when resigning or transferring from an SADF band. The reasons are rarely (if indeed ever!) the true ones. The departing one fabricates an excuse because were he to speak out honestly it would often be tantamount to adversely criticising a system represented by the very person who is going to have to write out his testimonial!

Job satisfaction is held to be desirable (sometimes even considered a 'right'). When this is denied, for whatever reason, then there is a growing cancer of discontent. The SADF bands do well to gaze across the waters, where the empiric approach evolved over many decades has proved efficient.

No writer in his right mind would be bold enough to align his efforts with those of the late Bertrand Russell, though if his subject matter were to be sufficiently contentious or critical as these pages suggest, then, he might dare to imagıne that he sat on the fringe of that delightful volume entitled Unpopular Essays ${ }^{8}$ which flowed from the pen of that philosopher par excellence some thirty years ago.

Unpalatable truths invariably invite either a cover-up or immediate change. But we must beware! - history shows that change tends to bring with it socio-economic upheaval. That is why any change suggested here needs be gradual, though inexorable, if it is to be calm and yet effective.

That change is desirable within bands has been appreciated, is revealed in a recent report by the Directorate of Organisation Studies. ${ }^{9}$ This report takes the form of a blue-print for the future. It lays down desirable paper qualifications (theoretical and practical) for players and conductors, together with relative ranks and pay. (It does not apply to existing personnel, except as an incentive perhaps to acquire papers). The report will however, if implemented, act as a filter through which to draw the military music personnel of the future. It would seem to be a desirable filter, though, as the vast majority of practical (useful) musicians hold no paper qualifications, the scheme is in danger of acting as a deterrent in an already dwindling supply market. The active musician, in all branches of the field, knows full well that the qualification for a player is: can he play and that the qualification for a conductor is: can he conduct! The highest paper qualifications need not relate to either activity.

The scheme, however, does not attempt to explain or solve the immediate problem of personnel turn-over; a problem which is seriously affecting some South African Military Bands.

Let us deal with this problem. Let us now present a revolutionary idea for setting military bands in South Africa upon a practical and progressive course towards, not only their well-being, but towards broadcasting standards. An interim idea, so to speak, which will not so much introduce change (with all its attendant dangers) as organise the existing situation. There will doubtless be a cry of 'Heresy!' from the cosily esconced, but, as an alternative to the present ennui and musical impasse, any idea is surely worth considering.

Let there be three corner-stone posts in each band: 


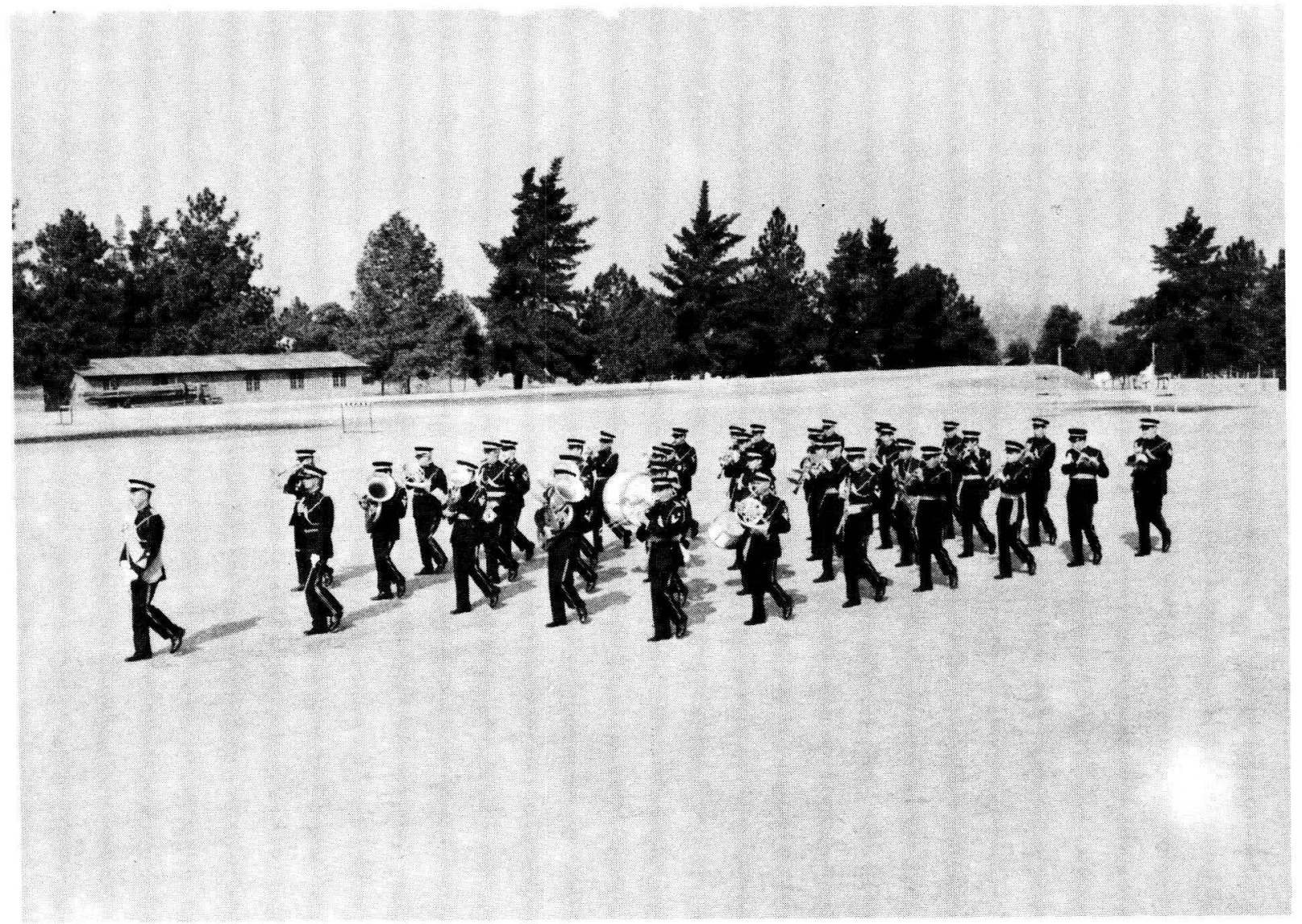

SAAF orchestra

(1) Business Administrator, doubling as Ceremonials charge d' affaires.

(2) Personnel Manager.

(3) Conductor, and musical trainer.

The crux of this vision is (3). It would be absolutely vital that the position be filled only after consulting the players. In support of this albeit heretical notion let Sir Thomas Beecham speak:

'Of a Performance I would put the opinion of the players over and above that of any outside person whomsoever he be and whatsoever his qualifications. ${ }^{10}$

We do well to remember that it is axiomatic that the quality of a performance is in direct ratio to the quality of the conductor. The conducting post would be widely advertised and auditions held. Furthermore, as a guard against mistakes (and first loves can sometimes end in divorce) the Conductor's contract would run for 12 months and be renewable subject to success.

But you can't run the Services like that (!) our esconced friends will gasp - but, our argument deals with musicians who are primarily musicians, and Servicemen only by necessity.

Our brief peace-time recommendations having run their gauntlet let us hazard a plan for the Military Band in War-time (or Border War, as we now have in South Africa). That military bands can be more fruitfully employed, and deployed, to the advantage of all, can scarcely be denied.

By splitting up into groups of four (or maximum, five) small mobile units could penetrate areas where isolated troops would welcome the diversion. The average military band can supply two or three such groups (Jazz; Dixieland; Oompah!) and still maintain a skeleton band at base to deal with routine duties.

In time of modern war one would expect musicians to be trained to act as stretcher bearers and to render First Aid. Are they so prepared? There is much to be said for this and nothing to be said against. If the bombs fall (as they did on London for four desperate years) such knowledge will be used thankfully. 

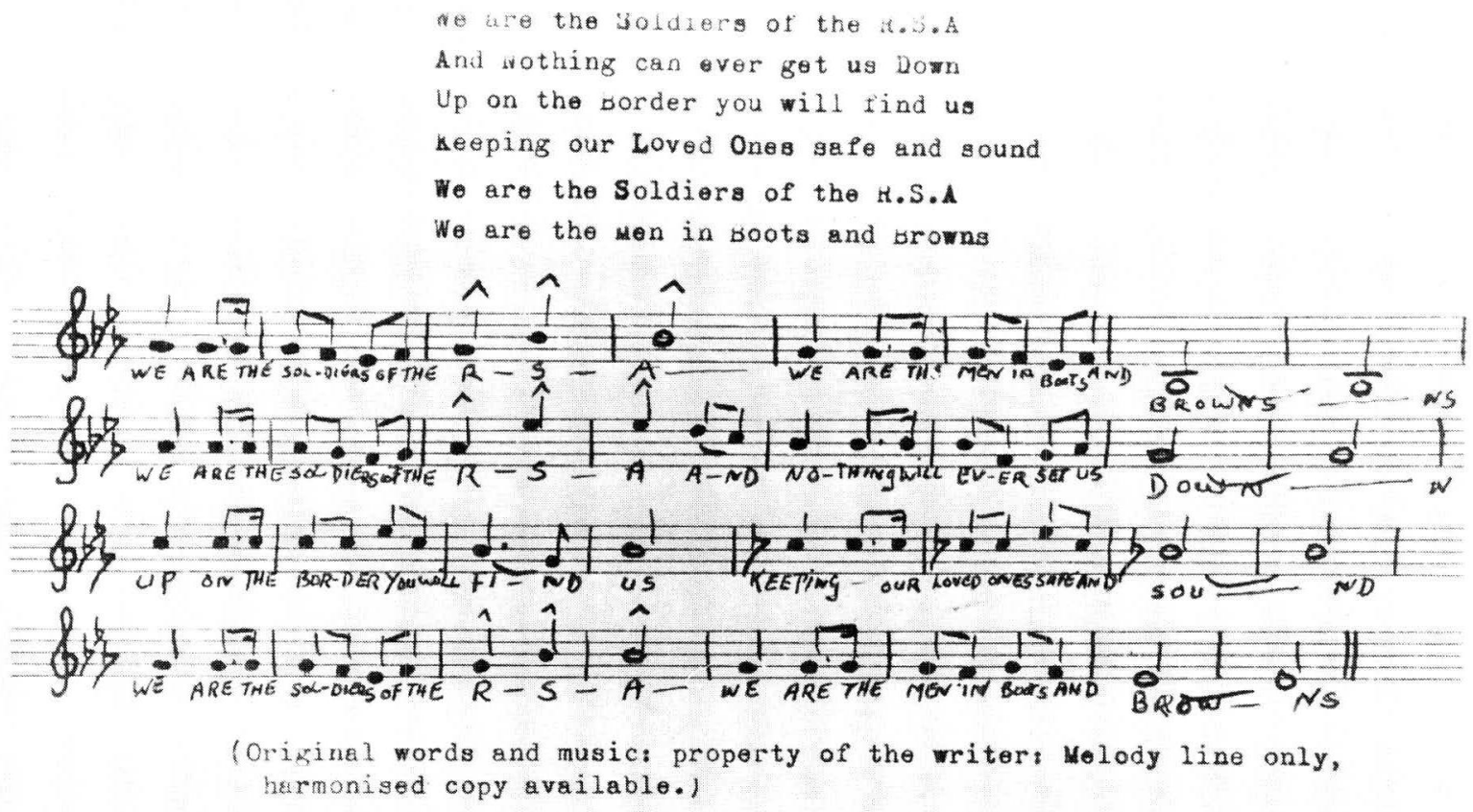

This writer will conclude with his own contribution to the morale building of the Infantryman - a Marching Song! We have observed that hostilities invariably produce such music. Perhaps it is no bad thing to prepare such contributions during the time of comparitive Peace - or, at least, attempt such preparation (!)

* Sgt F.A.M. Cousins is attached to the SA Army Orchestra.

** This article was one of the deserving entries for the military essay competition of 1979 .

\section{Footnotes:}

1. KAMAHAL - Australian aborigine singer (S.A.B.C T.V. 14/6/78)

2. The Black Watch: Philip Howard (1968: Hamish Hamilton, London)

3. The Highland Light Infantry: L. B. Oatts (1969: Leo Cooper, London)

4. A Lost Legionary in South Africa (Life at Roke's Drift): Col G.

5. Hamilton-Brown 1877-8 (T. Werner Laurie, Clifford's Inn, London)

5. Cliff Saunders: Radio and T.V. Magazine, October 1978 (9th-15th) p. 56

6. Motto of the Freemasons in France.

7. 1979 Edinburgh Tattoo brochure

8. Unpopular Essays: Bertrand Russell, Unwin, London 1950

9. Report on S.A. Corps of Bandsmen (Army) July 1979

10. A Mingled Chime: Autobiography, Sir Thomas Beecham, MacMillan. 